Ethiopian Journal of Environmental Studies \& Management 10(5): 610 - 617, 2017.

ISSN:1998-0507

doi: https://dx.doi.org/10.4314/ejesm.v10i5.5

Submitted: February 06, 2017 Accepted: June 13, 2017

\title{
CONSTRAINTS ASSOCIATED WITH PESTICIDE SAFETY MEASURES ADOPTION AMONG USERS IN OIL PALM FARMS IN EDO, DELTA AND ONDO STATES, NIGERIA
}

*OSABUOHIEN, J.I. AND OMOREGBEE, F.E.

Department of Agricultural Economics and Extension Services, University Benin, Benin City Nigeria

\begin{abstract}
Safety of farmers is basic to the realization of food security and agricultural transformation in developing countries globally. Most farming activities predispose farmers, non-farmers and farming communities to health hazards because some users of these hazardous substances deliberately refuse to observe necessary precautionary measures. This study assessed constraints associated with pesticide safety measures adoption among users of pesticides in oil palm farms in Edo, Delta and Ondo States. A multi-stage sampling technique was used to select 268 respondents. Questionnaire was used to collect primary data analyzed for this study using frequency counts, percentages, and means while Kruskal-Wallis test was used to examine the relationships between the response and predictor variables of the study. Results showed that about $95 \%$ of the respondents adopted the 28 identified pesticide safety measures. Nine constraints to pesticide users' adoption of pesticide safety measures were identified by respondents. Inconveniences of personal protective clothing on users $(\bar{X}=2.28)$, some pesticide safety measures are dangerous to man $(\bar{X}=2.16)$, and lack of money to buy protective equipment ( $\bar{X}=2.05$ ) were found to be serious constraints to adoption of safety measures. There was a significant difference in constraints to adoption among pesticide users in oil palm farms in the surveyed States $(H=9.524, P<0.05)$. It is recommended that safety measures should be included in agricultural messages disseminated to farmers especially those that use pesticides.
\end{abstract}

Key Words: Constraints, Pesticide, Safety Measures, Oil Palm, Adoption

\section{Introduction}

Agriculture had been identified as a driver of change, means of reducing poverty and ensuring food security in developing economies (Akpabio, 2012). It is a key occupation of most rural dwellers that produced most of the food consumed in Nigeria. For instance, Ekong (2010) stated that higher percentage of the people in Edo $(54.56 \%)$, Delta $(66.85 \%)$, and Ondo $(59.62 \%)$ live in rural areas and a reasonable number of these people are into agriculture and agriculture related activities for a living (Edo State, 35.5\%; Delta State, 44.1\%; Ondo State, 34.7\%). Nigeria agriculture relied heavily on small scale farmers who grow and rear

*Corresponding Author: Osabuohien, J.I.

Email: julius.osabuohien@ uniben.edu 
wide range of crops like oil palm that has benefited from man's efforts at boosting food sufficiency (Foundation for Partnership Initiative in the Niger Delta, FPIND, 2011).

Oil palm is an important crop and a source of revenue and income for owners and workers in oil palm farmers in Southeast, South-west, South-south, and some central States in Nigeria (NIFOR, 2005; Initiatives for Public Policy Analysis, IPPA. 2010). During Colonial era Nigeria was the highest producer of palm oil and palm kernel in the world contributing immensely to the nation's food security and employment (Jibowo and Aderinto, 2011). But this position had been lost to two Asian countries- Malaysia and Indonesia who now produce $85 \%$ of the world palm oil and kernel (Spore, 2013).

The foregoing is an indication that Nigeria oil palm agricultural subsector is in dire need of transformation to enable it regain this lost enviable position it attained during the colonial era to early part of the nation independence in October $1^{\text {st }} 1960$ (Jibowo and Aderinto, 2011). The transformation of this allimportant subsector in an exercise in the right direction as it will reduce food insecurity and unemployment in rural areas and contribute to the transformation of rural areas and the nation as there is a synergistic relationship existing between rural area and agricultural transformation (Nwachukwu and Ekanem, 2011). Strong and an efficient agricultural sector had been identified to be basic to a country ability to feed its growing population, generate employment, earn foreign exchange and provide raw materials for industries (Akpabio, 2012). There is no doubt about the fact that increased agricultural food output is capable of bringing about improvement in the welfare of the farmers thereby reducing poverty and food insecurity level that have been one of the key problems in Nigeria (Erie et al., 2011). But increase agricultural food output cannot be achieved without the safety of farm workers (farmers and hired workers) particularly as their safety had been pinpointed to be critical to the overall agricultural development and rural transformation (Ladele, 2005). But agriculture today had been described as a dangerous occupation that exposes millions of agricultural farmers, workers and other people to ill-health and even death throughout the world (Brown and Jacobson, 2005; Jensen et al., 2011; Olowogbon and Jolaiya, 2012). Similarly Health and Safety Executive (2009) reported that agriculture is an industry with high incidences of human accidence and ill health. Farmers' illness and disease problems are capable of reducing agricultural productivity through the loss of human labours, knowledge of productive adults and their assets with which they cope with illness (Spore, 2009; Sharma et al., 2010; Ulimwengu and Badiane, 2011).

The desire for food, a container of minerals for man's health and survival made the early-man to wander to gather wild fruits and animals and the modern man to fathom and develop better methods and technologies like pesticide, a resource, to aid agricultural food production. The progressive changes in each historical era of agricultural development clearly show man's desire to produce enough food.

Pesticide was introduced into oil palm production to protect it against pests that are inimical to its production 
particularly young oil palms in the nursery but chemical pesticide has become source of human and environmental poisoning (NIFOR, 2005; Aghasi et al., 2010). Chemical pesticides are capable of having negative effect on all categories of humans particularly those persons who mix, load, spray, transport and use these chemicals. Some of the identified pesticide routes of entrance into human's bodies to be: oral, swallowing pesticide liquid, dust or solid through mouth or nose; dermal or skin, respiratory, by breathing into their body pesticide dust, vapour or spray; ocular, and through the eyes (Shrivastava, 2004).

The common manifestations of pesticides human exposures are acute health problems on vital parts of the body (i) General: extreme weakness and fatigue; Skin: irritation, burning sensation, excessive sweating, staining; (ii) Eyes: itching, burning sensation, watering, difficult or blurred vision, narrowed or widened pupils; (iii) Digestive system: burning sensation in mouth and throat, excessive salivation, nausea, vomiting, abdominal pain, diarrhea; (iii) Nervous system: headaches, dizziness, confusion, restlessness, muscle twitching, staggering gait, slurred speech, fits, unconsciousness; (iv) Respiratory system: cough, chest pain and tightness, difficulty with breathing, wheezing and others.

Increasing incidences of human pesticide-related morbidity, mortality and environmental poisoning in coastal areas especially Niger Delta States of Nigeria had been attributed to deliberate refusal of some pesticide users to adhere to stipulated pesticide safety precautions (Ogunjimi and Farinde, 2012).
Farmers' safety is basic to achieving the goal of agricultural transformation agenda globally. Adoption of proven agricultural related scientific and technological innovations remain one of the surest ways of boosting food security in the world especially in Nigeria where food insecurity is a major problem and pesticides poison has become source of human and environmental hazards (PAN, 2007).

In view of the foregoing, this study seeks to assess the constraints associated with pesticide safety measures adoption among users in oil palm farms. The objectives of the study were to: ascertain users' sources of awareness of pesticide safety measures, and identify constraints to adoption of pesticide safety measures. The study hypothesized that there is no significant difference among the surveyed States in terms of constraints to adoption of pesticide safety measures.

\section{Material and Methods}

This study was carried out in Edo, Delta and Ondo States in the Niger-Delta region, Nigeria. Ondo State is the highest producer of oil palm in the southwest States, Edo and Delta States are key producers in the South-South States (NIFOR，2005; FGN， 2006; FPIND, 2011).

Nigeria oil palm producing States were stratified into three based on delineated area under oil palm production in Niger Delta area of Nigeria (FPIND, 2011): less than 20000 ha, 20,000 ha to 50,000 ha and above 50,000 ha. Simple random sampling technique was used to select the three States from each of the stratum. Oil palm farms were grouped into three clusters on the basis of ownership: government, multinational 
and small/medium in each State. For the purpose of this study one government and two multi-national oil palm farms were selected from the three States while a snowballing sampling technique was used to select five small and medium scale oil palms from Edo and Ondo States and six from Delta State. Simple random sampling technique was used to select respondents from units, departments or sections of the government and multinational plantations were they were assigned while selection of all pesticide users were carried in situation were pesticide users are less than 11 in units, departments, and sections as asserted by Owie (2006). The total respondents sampled for this study was 268. Descriptive statistics and Kruskal-Wallis test were employed in the analyses of the data.

\section{Measurement of Variables}

To measure adoption $\left(\mathrm{Y}_{2}\right)$ of pesticide safety measures, respondents were requested to indicate Yes (score 1) for any of the 28 identified pesticide safety measures adopted by them and No (score 0) if otherwise.

A list containing 9 identified constraining factors to pesticide safety measures (Inconvenience of pesticide protecting clothes on users, It is dangerous to humans and environment, Finance, Little or no-extension expertise advice, I don't know how to use them, No access to pesticide safety measures, Lack of training on how to use pesticide safety use, Inability to read, and It is against my cultural belief, were made available to respondents to tick the options that are constraint to their use of pesticide safety measures. The respondents' constraints to adoption of pesticide safety measures were measured in 3-point rating scale: very serious (score 3), serious (score 2), and not serious (score 1). Mean $(3+2+1=6 / 3) 2.0$ and standard deviation were estimated for each constraint. A constraint item with a mean score of 2.0 and above implies that the constraint was serious while a score below 2.0 implies otherwise.

Kruskal-Wallis test ( $\mathrm{H}$ test): It compares more than two samples that are independent, or related. The test is used when the examined groups are unequal size, and to ascertain whether samples originated from the same distribution as was also used by Chakrabarty (2007).

The Kruskal-Wallis standard model is:

$$
\mathrm{H}=\frac{12}{N(N+1)} \sum_{i=1}^{C} \frac{R_{1}^{2}}{n_{i}}-3(N+1)
$$

Where

$\mathrm{H}=$ Kruskal-Wallis test

$\mathrm{N}=$ Sum of all observations in all samples combined

$\mathrm{n}_{\mathrm{i}}=$ number of observations in the ith grouping

$\mathrm{C}=$ Total number of samples in the study

$\mathrm{R}^{2}=$ Sum of ranks

$\mathrm{i}=$ Sample number in the study 


\section{Results and Discussion}

Source of Awareness of Pesticide Safety Measures

The results for respondents' source of information on pesticide safety measures shown in Table 1 indicates that $96.6 \%$ of the respondents derived their information from pesticide container labels, $91.0 \%$ from pesticide specialists and pesticide company representatives while those who got their information from pesticides vendors and family/community members accounted for $77.6 \%$.

On State wise, Edo State respondents derived their pesticide information majorly from pesticide containers' labels (95.3\%) while those in Delta and Ondo
States derived theirs majorly from extension agents (100\%) and labels (100\%) respectively. According to Duus et al. (2012), farmers could also get pesticide dosage information from pesticide labels. The high awareness percentage score (77.6 - 96.6\%) of each of the eleven sources of awareness was a pointer to the fact that respondents derived their safety measure information from different sources (Aarts and Woerkum, 1995). The respondents' different sources of information on pesticides safety measure is expected to enhance their awareness which may subsequently lead to their adoption of pesticide safety measures.

Table 1: Respondents' source of pesticide information

\begin{tabular}{|c|c|c|c|c|c|c|c|c|}
\hline & \multicolumn{2}{|l|}{ Edo } & \multicolumn{2}{|c|}{ Delta } & \multicolumn{2}{|c|}{ Ondo } & \multicolumn{2}{|c|}{ Pooled } \\
\hline & Feq & $\%$ & Feq & $\%$ & Feq & $\%$ & Feq & $\%$ \\
\hline Label & 81 & 95.3 & 109 & 95.6 & 69 & 100 & 259 & 96.6 \\
\hline Extension agents & 59 & 69.4 & 114 & 100 & 69 & 100 & 232 & 85.6 \\
\hline Pesticide specialists & 77 & 90.6 & 100 & 87.7 & 67 & 97.1 & 244 & 91.0 \\
\hline Pesticide & & & & & & & & \\
\hline representatives & 21 & 24.7 & 95 & 83.3 & 68 & 98.6 & 244 & 91.0 \\
\hline $\begin{array}{l}\text { Lectures/seminars/conference } \\
\text { s/etc }\end{array}$ & 57 & 67.1 & 104 & 91.2 & 58 & 84.1 & 219 & 81.7 \\
\hline $\begin{array}{l}\text { Newspapers/Extension } \\
\text { publications }\end{array}$ & 60 & 70.6 & 102 & 89.5 & 68 & 98.6 & 230 & 85.8 \\
\hline Radio & 21 & 24.7 & 102 & 89.5 & 49 & 71.0 & 239 & 89.2 \\
\hline TV & 40 & 47.1 & 101 & 88.6 & 54 & 78.3 & 235 & 87.7 \\
\hline Other oil palm farmers & 57 & 67.1 & 100 & 87.7 & 59 & 85.5 & 216 & 80.6 \\
\hline Pesticide vendors & 55 & 64.7 & 108 & 94.7 & 40 & 58.0 & 208 & 77.6 \\
\hline Family/Community members & 39 & 45.9 & 111 & 97.4 & 48 & 69.6 & 208 & 77.6 \\
\hline
\end{tabular}

\section{Constraints to Respondents' Adoption of Pesticide Safety Measures}

The constraints which limit respondents' adoption of pesticide safety measures are shown in Table 2. At the aggregate level, the three most serious constraints factors faced by respondents were inconvenience of personal protective clothing on users $(\bar{X}=2.28)$, some pesticide safety measures are dangerous to man $(\bar{X}=2.16)$, and lack of money to buy protective equipment $(\bar{X}$ $=2.05$ ). These were considered serious constraints by farmers as the respective 
mean values was higher than 2.00 while inability to $\operatorname{read}(\bar{X}=1.70)$ and it is against my cultural belief $(\bar{X}=1.42)$ were least constraints identified as their mean scores were less than 2.00. On individual state basis, inconvenience of personal protective clothing on users was also found to be a major constraint in the three surveyed States. Edo State respondents experienced more serious constraints to adoption of pesticide safety measures having had over 2.00 mean scores in 5 of the 9 identified constraints as against
Ondo and Delta States with mean scores of $\geq 2.00$ in only 2 and 3 identified constraints. The high number of constraint factors to Edo State respondents' adoption of pesticide safety measure may have been due to the high level of respondents with low educational status using pesticides (Osabuohien, 2014). This finding agrees with Jan et al. (2011) that adoption of pesticide safety measures is hindered by different constraints.

Table 2: Constraints to respondents' adoption of pesticide safety measures

\begin{tabular}{|c|c|c|c|c|c|c|c|c|}
\hline \multirow{3}{*}{$\begin{array}{l}\text { Inconveniences of pesticide safety } \\
\text { clothing on its users }\end{array}$} & \multirow{2}{*}{$\begin{array}{l}\text { Edo } \\
\text { Mean }\end{array}$} & \multirow{2}{*}{ SD } & \multirow{2}{*}{$\begin{array}{l}\text { Delta } \\
\text { Mean }\end{array}$} & \multirow{2}{*}{ SD } & \multirow{2}{*}{$\begin{array}{l}\text { Ondo } \\
\text { Mean }\end{array}$} & \multicolumn{3}{|c|}{ Pooled } \\
\hline & & & & & & SD & Mean & SD \\
\hline & $2.36^{*}$ & .65 & $2.27 *$ & .83 & $2.20 *$ & .87 & $2.28 *$ & 0.79 \\
\hline $\begin{array}{l}\text { Some pesticide safety measures are } \\
\text { dangerous to man }\end{array}$ & $2.19 *$ & 75 & 1.89 & 82 & $2.58 *$ & .85 & $2.16^{*}$ & 0.85 \\
\hline $\begin{array}{l}\text { Lack of money to buy protective } \\
\text { equipments }\end{array}$ & $2.45^{*}$ & .65 & 1.96 & .89 & 1.71 & .86 & $2.05^{*}$ & 0.86 \\
\hline Little/no extension expertise advice & $2.16^{*}$ & .72 & $2.07 *$ & $\begin{array}{l}3.0 \\
3\end{array}$ & 1.64 & .82 & 1.99 & 2.07 \\
\hline I don't know how to use them & 1.95 & .67 & 1.74 & .79 & $2.32 *$ & .83 & 1.96 & 0.80 \\
\hline No access to pesticides safety measures & 1.93 & .83 & 1.88 & .97 & 1.35 & .72 & 1.76 & 0.90 \\
\hline Inability to read & $\begin{array}{l}2.11 * \\
1.69\end{array}$ & $\begin{array}{l}.76 \\
74\end{array}$ & $\begin{array}{l}1.71 \\
1.74\end{array}$ & $\begin{array}{c}82 \\
83\end{array}$ & $\begin{array}{l}1.43 \\
1.65\end{array}$ & $\begin{array}{r}.61 \\
85\end{array}$ & $\begin{array}{l}1.76 \\
1.70\end{array}$ & $\begin{array}{l}0.79 \\
0.81\end{array}$ \\
\hline It is against my cultural belief & 1.31 & .56 & 1.56 & .73 & 1.32 & .61 & 1.42 & 0.66 \\
\hline
\end{tabular}

\section{Results of Hypothesis Tested}

Kruskal-Wallis test (H-value) $(\mathrm{df}=2$, $\mathrm{N}=268)=9.524,0.009<0.05)$ in Table 3 implies a significant difference existed between the States in terms of constraints to adoption of pesticides safety measures. The null hypothesis was therefore rejected at $5 \%$ while the alternative hypothesis accepted. 
Table 3: Difference in respondents' constraint of pesticide safety measures by state

\begin{tabular}{llll}
\hline Total observation & Test statistic $(\mathrm{H})$ & Degree of freedom & Asymptotic sig. (2-sided test) \\
268 & 9.524 & 2 & 0.009 \\
\hline
\end{tabular}
$5 \%$ Critical $\mathrm{H}=5.99$,

\section{Conclusion}

This study has demonstrated that pesticide users in oil palm farms in the surveyed States faced different levels of constraints to adopting pesticide safety measures. Since the basic constraints was that pesticide safety clothing were perceived to be inconveniencing on the users, the study therefore recommended that pesticide safety measures should be made a key extension package to farmers in the study areas.

\section{References}

Aarts, N. and van Woerkum, C.M.J. (1995). The communication between farmers and government about nature. European Journal of Education and Extension. 2(2):110.

Aghasi, M.Z., Hashim, S.M., Omar, D. and Mehrabani, M. (2010). Sociodemographic characteristics and Safety Practices in Pesticide Applications in Zangiabad Area of Iran. Australian Journal of Basic and Applied Sciences, 4(11): 5689 5696.

Akpabio, I.A. (2012). Youth employment and agricultural development: The inextricable siamese twins. $34^{\text {th }}$ Inaugural Lecture Series University of Uyo, September $27^{\text {th }}$

Brown, E. and Jacobson, M.F. (2005). Cruel oil How palm oil harms health, rainforest and wildlife www.cspinet.org Accessed on September $2^{\text {nd }}, 2012$
Chakrabarty, D. (2007). Comparative utilization of phosphorus from sedimentary and igneous phosphate rock by major biotic components of aquatic ecosystem. Int, J. Environ. Sci. Tech., 4(1): 43-48.

Ekong, E.E. (20I0). Rural Sociology $\left(4^{\mathrm{Th}}\right.$ Edition) Dove Educational Publishers, Uyo Nigeria. Pp. 1-258

FGN-Federal Government of Nigeria (2006). Niger Delta regional development master plan River State, Nigeria. Printing Development Company limited. Pp $1-89$.

Foundation for Partnership Initiatives in the Niger Delta, FPIND (2011). A report on palm oil value chain analysis in the Niger Delta http:pindfoundation.net/wpcontent/uploads/palm\%20OilValue $\% 20$ chain\%20Analysis.pdf Accessed 28/02/2012

Health and Safety Executive (2009). Understanding and influencing farmers' attitudes RR700 Research Report. BOMEL Limited, United Kingdom www.hse.gov.uk

Initiative for Public Policy Analysis (IPPA, 2010). Palm oil and economic development in Nigeria and Ghana, recommendation for the World Bank's 2010 palm oil strategies._www.ippanigeria.org

Jan, M., Sultan, K. and Ali, S. (2012). "Role of communication in diffusion and adoption of agricultural innovations. Gomal 
Constraints Associated with Pesticide Safety Measures.................OSABUOHIEN \& OMOREGBEE

University Journal of research 27 (1): $111-118$

Jensen, H.K., Konradsen, F., Jørs, E., Petersen, J. H., Anders, A. (2011). Pesticide use and self-reported symptoms of acute pesticide poisoning among aquatic farmers Journal of Phnom Penh Toxicology Accessed on $3^{\text {rd }}$ January, 2010 from http://www.hindawi.com/journals/jt /2011/639814/cta

Nigerian Institute for Oil Palm Research (NIFOR) (2005). Briefing on the institute and highlights of achievements in research and production. Nigerian Institute for Oil Palm Research, Benin City

Ogunjimi, S.I. and Farinde, A.J. (2012). Farmers' knowledge level of precautionary measures in agrochemicals usage in cocoa production in Osun and Edo states, Nigeria International Journal of Agriculture and Forestry 2(4): 186194.

Olowogbon, S.T. and Jolaiya, A.J. (2012). Economics in occupational health and safety: The agricultural perspectives. In: African Newsletter on occupational health and safety 22(1): $9-11$

Owie, I. (2006). Fundamentals of statistics in education and the social sciences $\left(3^{\text {nd }}\right.$ Ed), Lagos National Book Consortium Pp 142-163

Pesticides Action Network (2007). Strategic assessment of the status of POPs pesticides trading in south western Nigeria. Accessed on the $5^{\text {th }}$ May 2011 from $w w w . P A N$ UK.org/archieve/project/obsolete

Shrivastava, A. K. (2004). Agriculture and food. New Delhi, Indian A.P H. publishing corporation. Pp 208

Spore (2009). Land transfer. Consulting rural communities No 142 page 8-9

Spore (2013). Blue Economy in Crisis? http://Spore cta. Number 163

Ulimwengu, J. and Badiane, O. (2011). Vocational training and agricultural productivity: Evidence from rice production in Vietnam Accessed on $20^{\text {th }} \quad$ February 2012 from http://www.tandfonline.com/loi/rae $\underline{e 20}$ 